\title{
Personality traits as predictors of occupational accident rates among workers of Khorasan Petrochemical Company, Iran
}

\author{
Rahimi-Pordanjani T, $\mathrm{PhD}^{1 *}$, Mohamadzade-Ebrahimi A, $\mathrm{PhD}^{1}$, Rahimi-Pordanjani $\mathrm{H}, \mathrm{PhD}^{2}$ \\ 1- Assistant Prof., Dept of Psychology, Faculty of Humanities, University of Bojnord, Bojnord, Iran. 2- PhD Student in Art \\ History, Dept of Art History, Faculty of Art, Shahed University, Tehran, Iran.
}

\begin{abstract}
Received: January 2015, Accepted: February 2015

Background: Approximately, $90 \%$ of workplace accidents are due to human errors. The study of the relationship between individual differences and accidents and injuries are beneficial in the prevention of these accidents. The aim of the present study was to examine the relationship between extraversion, agreeableness, conscientiousness, and neuroticism and occupational accident rates in the petrochemical industry.

Materials and Methods: This was a descriptive correlational study. The study population consisted of line employees of Khorasan Petrochemical Company in Bojnourd, Iran ( $\mathrm{n}=1160)$; 300 employees were selected using stratified random sampling. Data collection tools consisted of the NEO FiveFactor Inventory and Incident Reporting Rate Scale. In order to analyze the data, regression analysis and to validate the results, confirmatory factor analysis were performed using AMOS 21 software.

Results: Findings indicate that correlation coefficients between the five-factor personality traits and occupational accident rates were significant $(\mathrm{P}<0.001)$. In stepwise multiple regression analyses, of the 5 independent variables, only the 2 variables of conscientiousness and agreeableness found permit entry into the regression equation $\left(\mathrm{R}^{2}=0.186, \mathrm{P}<0.001\right)$.

Conclusions: The results of this study showed the importance of conscientiousness and agreeableness as predictors of occupational accident rates. Therefore, in order to select people for working in high risk environments, such as the petrochemical industry, we should rely on these variables.
\end{abstract}

Keywords: Occupational Accident, Personality, Extraversion, Neuroticism

\section{Introduction}

Psychological research has shown that personality factors influence safety-related behaviors (1). In fact, the first involvement of psychology in safety focused on finding the "injury-prone" personality (2). Some researchers have suggested that $90 \%$ of accidents and injuries can be attributed to human error (3-6). The study of the relationship between individual differences and accidents and injuries has received little attention. Most safety researchers have focused on organizational influences to further reduce the costs of occupational accidents and injuries (7). Hansen discusses a number of individual difference variables that could be related to accidents and injuries (1). These include physical characteristics of workers, education, marital status, perceptual and mental abilities, and personality traits. The five-factor model (FFM) or "Big Five" was first proposed over 60 years ago, but has only recently reappeared in the personality literature. In 1980, Goldberg aided by Costa and McCrae developed the Big Five model (8). The five-factor personality traits consist of extraversion, agreeableness, iconscientiousness, neuroticism, and openness to experience (9). Although all dimensions have been studied in accident/injury research, conscientiousness, extraversion, agreeableness, and neuroticism have received the most attention (8). Conscientious employees are expected to follow safety precautions and not act impulsively and thus lessen the risk of injury.

\footnotetext{
Corresponding author: Tayebeh Rahimi-Pordanjani, Dept of Psychology, Faculty of Humanities, University of Bojnord, Bojnord, Iran.

Email: Tayebe.Rahimi@yahoo.com
} 
They may also demonstrate greater selfdiscipline and control. Extraverts are viewed as more outgoing, social individuals. However, extreme extraversion, marked by over confidence, intolerance, and aggression, is thought to increase the risk of accidents due to risk taking behaviors and carelessness. Introverts are more internally controlled and as such are expected to be more vigilant in performing tasks (1). Disagreeable individuals are frequently viewed as social misfits and often exhibit negative, hostile emotions at work. Finally, individuals exhibiting neurotic behaviors such as anxiety and nervousness are thought to be more susceptible to accidents (8).

These finding have been demonstrated in many studies, although not all consistently within the same study. Lajunen looked at traffic and occupational fatalities and found that extraversion positively correlated with traffic accidents, although neuroticism was negatively associated with accidents (10). A study of 23 managers at a manufacturing plant found that managers demonstrating traits related to neuroticism (anxiety and nervousness) had higher injury rates in their departments (11). In contrast, departments with managers who exhibited traits of conscientiousness and extraversion were inversely associated with injury rates (11). Moreover, a study of university undergraduates found that students who demonstrated greater characteristics of conscientiousness and agreeableness were less likely to be involved in any accident. However, no significant relationship was found between neuroticism, extraversion, and openness to experience and accidents (12).

The aim of the present study was the examination of the relationship between personality traits (extraversion, agreeableness, conscientiousness, and neuroticism) and occupational accident rates. Previous studies have been mainly focused on particular industries, and no attempt has been made to describe the relationship between the five factor personality traits and occupational accident rates among petrochemical industry workers. Furthermore, to our knowledge, no research has been performed in Iran to investigate the relationship between personality traits and occupational accident rates; thus, the present study is new in this respect.

\section{Materials and Methods}

In this cross-sectional study, the study population consisted of all line employees of the Khorasan Petrochemical Company in Bojnourd, Iran, during 2013 ( $\mathrm{n}=1160)$. Using the Krejcie and Morgan Table (13), 300 employees were selected. First, subjects were selected by accessing the list of employees referred to the public relations department. Then, they were selected using stratified random sampling method. Next, a meeting was held with all managers and supervisors of various departments of the organization and the list of selected subjects from each department was presented. Subsequently, each employee received the questionnaire in person in their workplace and completed and returned it to the researcher. Signed, written informed consents were obtained from all participants of the study. Data was collected using the NEO Five-Factor Inventory and Incident Reporting Rate Scale.

\section{Personality Five Factor Inventory (NEO)}

The short form of the NEO Five-Factor Inventory is a 60-item questionnaire measuring five dimensions of the normal personality; neuroticism, extraversion, openness, agreeableness, and conscientiousness (14). Respondents indicate their degree of agreement with each item on a 5-point Liker-type scale. In this study, the Persian translation of the NEO Five-Factor Inventory by Kiamehr (14) was used. Standardization of the NEO Five-Factor Inventory was accomplished using a group of humanities students from Universities of Tehran, Iran. Alpha estimates for the Persian 
version were $0.79,0.76,0.78,0.54$, and 0.61 for neuroticism, extraversion, openness, agreeableness, and conscientiousness, respectively (15).

\section{Incident Reporting Rate Scale}

This questionnaire is a tool made by Barling, Loughlin, and Kelloway for collecting data about the rate of incident reporting. It includes 3 components, namely physical symptoms, psychological symptoms, and accident (16). This questionnaire has high internal reliability (Cronbach's $\alpha=70 \%$ to $80 \%$ ) and a desirable validity (17). Kiani et al. performed as study using this questionnaire in Isfahan Steel Company, Iran, and calculated internal reliability coefficients and gained a Cronbach's alpha of 0.83 for the questionnaire (18). In the current research, internal reliability coefficients (Cronbach's $\alpha$ ) of the questionnaire and its components (physical symptoms, psychological symptoms, and accident) were respectively calculated at 0.93 , $0.86,0.87$, and 0.85 . In addition, in this study, construct validity was calculated using confirmatory factor analysis (CFA). The results indicated a reasonable fit, and normed $\chi^{2}$ measure $\left(\chi^{2} / \mathrm{df}\right)=3.65$, normed fit index $(\mathrm{NFI})=0.83$, incremental fit index $(\mathrm{IFI})=$ 0.87 , comparative fit index $(\mathrm{CFI})=0.87$, rootmean-square error of approximation (RMSEA) $=0.09$, and Tucker-Lewis index $(\mathrm{TLI})=0.84$.

\section{Results}

\section{Part I: Demographic characteristics of participants}

Research findings are presented in 3 sections; demographic findings, descriptive findings, and the findings relevant to regression analysis. Demographic characteristics of participants are shown in table 1.

Table 1: Demographic characteristics of the subjects $(n=300)$

\begin{tabular}{lcc}
\hline & & $\begin{array}{c}\text { Frequency } \\
\text { Percentage \% }\end{array}$ \\
\hline Age (year) & $18-25$ & 2 \\
& $26-33$ & 23 \\
& $34-42$ & 38 \\
Sex & $43-49$ & 32 \\
& 50 and higher & 5 \\
\hline Marital & Male & 98 \\
status & Female & 2 \\
\hline & Married & 93 \\
Education & Single & 7 \\
& Master degree & 2 \\
& University graduates & 32 \\
\hline \multirow{2}{*}{ Hork } & High school graduates & 17 \\
experience & Primary school graduates and lower & 49 \\
(year) & 5 and lower & 14 \\
& & \\
& & 15 \\
Shift status & 6-10 & 17 \\
& $11-15$ & 41 \\
\hline
\end{tabular}




\section{Part II: Descriptive statistics}

Descriptive findings, consisting of the means, standard deviations, and internal correlation of the research variables (neuroticism, extroversion, openness, agreeableness, conscientiousness, and occupational accident rates) are presented in table2.

Table 2: Means and standard deviations of Big Five personality factors

\begin{tabular}{llccccccc}
\hline & \multicolumn{7}{c}{ correlations } \\
\hline & & $\overline{\mathbf{X}}$ & SD & $\mathbf{1}$ & $\mathbf{2}$ & $\mathbf{3}$ & $\mathbf{4}$ & $\mathbf{5}$ \\
$\mathbf{1}$ & neuroticism & 17.01 & 6.39 & 1 & & & & \\
$\mathbf{2}$ & extroversion & 28.89 & 4.26 & -0.513 & 1 & & & \\
$\mathbf{3}$ & agreeableness & 31.82 & 5.37 & -0.503 & 0.304 & 1 & & \\
$\mathbf{4}$ & conscientiousness & 36.00 & 6.75 & -0.471 & 0.470 & 0.703 & 1 & \\
$\mathbf{5}$ & Occupational accident rates & 17.12 & 7.21 & 0.242 & -0.153 & -0.392 & -0.404 & 1 \\
\hline
\end{tabular}

Table 2 indicates that the correlation coefficient between occupational accident rates and neuroticism is 0.242 , extroversion is -0.153 , agreeableness is -0.392 , and conscientiousness is -0.404 , all of which are statistically significant $(\mathrm{P}<0.001)$. These results confirm all hypotheses. The results of the fifth hypothesis, i.e.

there is a multiple correlation between neuroticism, extroversion, agreeableness, and conscientiousness and occupational accident rates, are presented in part III.

\section{Part III: Regression Analysis}

To assess the predictive power of the Big Five personality factors in terms of occupational accident rates, regression analysis was performed. The results are presented in table 3. The results of the stepwise multiple regression analysis indicate that neuroticism, extroversion, agreeableness, and conscientiousness have significant multiple correlation with occupational accident rates, which is equal to 0.431 . These results explain $18.6 \%$ of variance in the criterion variable.

Table 3: The result of the stepwise multiple regression analysis of personality traits with occupational accident rates

\begin{tabular}{lccccc}
\hline & MR & RS & F & t & p \\
\hline conscientiousness & 0.404 & 0.163 & 51.24 & -3.23 & 0.001 \\
agreeableness & 0.431 & 0.186 & 29.96 & -2.72 & 0.007 \\
\hline
\end{tabular}

\section{Discussion}

The purpose of this study was to investigate the relationship of Big Five personality traits with occupational accidents. The results of simple correlation indicate that neuroticism has a significant positive correlation with occupational accidents. The correlation coefficient was 0.242. These results are consistent with findings of Henning et al. (19), Beecher et al. (20), and Samavatian et al. (22). However, they are inconsistent with findings of some other researchers $(1,8,10,11,23)$. Individuals with high levels of neuroticism are more likely to be anxious, depressed, and insecure (14). Neuroticism also reflects low stress tolerance; therefore, neurotic individuals are more likely to become flustered or frantic due to job demands, resulting in a reduction in attention and focus at work. Thus, neuroticism is expected to relate positively to occupational accidents (19). Nevertheless, results for neuroticism were mixed; some researchers stated that although increased anxiety is felt to 
divert attention from tasks at hand leading to accidents, neurotic behavior may instead lead to fewer accidents because heightened anxiety may contribute to greater concentration (1).

The results also indicate that extroversion has a negative and significant correlation with occupational accident. The correlation coefficient was -0.153 . These results are consistent with findings of Hansen (1), Geller and Wiegand (2), Thoms and Venkataraman (12), and Henning et al. (19). Nonetheless, these findings are inconsistent with that of Lajunen (10) and Foster (24). The results for extroversion were mixed. Studies have shown that extreme extraversion, marked by over confidence, intolerance, and aggression, is thought to increase the risk of accidents due to risk taking behaviors and carelessness. Introverts are more internally controlled and as such are expected to be more vigilant in performing tasks (1). Moreover, studies have shown that extrovert individuals are likely to engage others in conversation, seek attention, and compete with coworkers. Although these characteristics prove beneficial in some work contexts, they may also lead to unsafe behaviors. Over long periods of time, regular unsafe behaviors are likely to result in safety incidents (24). On the other hand, research has supported the theory that the Big Five measure focuses on the sociable nature of extraverts more than on their thrill-seeking nature. It may be the case that extraverts are more attuned to safety conditions and have more positive attitudes toward safety. This may be due to their numerous social connections which may make them feel more personally responsible for the wellbeing of others (19).

The results also show that agreeableness has a negative significant correlation with occupational accidents. The correlation coefficient was -0.392 . These findings are compatible with those of Henning et al. (19), Morgan (8), and Clarke (25). Those with the agreeableness trait also exhibit cooperation, empathy, selflessness, and identification with others. Previous studies have shown low agreeableness to be related to workplace accident involvement. In the workplace, agreeable and altruistic individuals may feel responsible for their colleagues, which results in more positive safety attitudes (19).

In addition, our findings show that conscientiousness has a negative significant correlation with occupational accidents. The correlation coefficient was -0.404 . These findings are in agreement with those of Morgan (8), Henning et al. (19), Wallace and Chen (21), and Samavatian et al. (22). Those with the conscientiousness trait display competence, self-discipline, and dutifulness. Self-control, integrity, and honesty are important characteristics in conscientiousness. Conscientious employees are expected to follow safety precautions and not act impulsively, and thus, lessen the risk of injury. They may also demonstrate greater selfdiscipline and control (8).

Considering the results of the present study regarding the role of individual differences in the prediction of occupational accident rates, organizations should, before employing individuals for hazardous occupations, identify those with conscientiousness and agreeableness traits using the Big Five Personality Inventory. It is important to highlight some limitations of the present study which may prove useful in future research. First, the use of self-report measures may have inherent limitations (e.g. inability to recall and social desirability). A combination of selfreport questionnaires and objective assessments would be ideal. Second, the results obtained in this research are neither limited to the studied organization nor necessarily applicable to all organizations with different characteristics. Finally, the current results should be carefully interpreted. The causal relations between personality traits and occupational accident rates should be clarified using a longitudinal study design.

\section{Conclusion}

Our research shows that individual differences in personality can predict the rate of accidents 
and injuries. This research stands in contrast to previous findings showing little to no relationships between individual personality measures and occupational accident rates. By identifying critical antecedents to occupational accident rates and combining results across multiple personality facets, organizations can identify individual traits likely to result in or prevent accidents and injuries in industries, organizations, and jobs.

\section{Acknowledgement}

This study was supported by the Khorasan Petrochemical Company. Thanks are due to all workers who participated in this survey. Many thanks also go to the Department of HSE of Khorasan Petrochemical Company.

Conflict of interests: None declared.

\section{Reference}

1- Hansen CP. Personality characteristics of the accident involved employee. J Bus Psychol 1988; 2: 346-365.

2- Geller ES, Wiegand DM. People-based safety: Exploring the role of personality in injury prevention. Prof Saf 2005; 50(12):28-36.

3- Geller ES. The psychology of safety Handbook. Boca Raton, Florida: Lewis Publishers 2001. Chapter 4; P 58-86.

4- Seo DC. An explicative model of unsafe work behavior. Saf Sci 2005; 43:187-211.

5- Cooper MD. Behavioral safety interventions: A review of process design factors. Professional safety 2009; Feb:36-45.

6- Buck AM. Proactive personality and big five traits in supervisors and workgroup members: Effects on safety climate and safety motivation. [PhD thesis]: Oregon, Portland: Portland State University; 2011.

7- Shannon HS, Mayr J, Haines T. Overview of the relationship between organizational and workplace factors and injury rates. Saf Sci 1997; 26(3):201217.

8- Morgan SH. Personality traits as risk factors for occupational injury in health care workers. [PhD thesis]. Florida: University of Florida; 2007.

9- James LR, Mazerolle MD. Personality in work organizations. Thousand Oaks, CA: SAGE Publications, Inc 2002: DOI: http://dx.doi.org/10.4135/9781452231198
10- Lajunen T. Personality and accident liability: are extraversion, neuroticism and psychotics related to traffic and occupational fatalities? Pers Individ Dif. 2001; 31(8):1365-73.

11- Thoms P, Venkataraman RR. Relation of managers' personality to accident and injury rates. Psychol Rep 2002; 91(3 Pt 2):1107-15.

12- Cellar DF, Yorke CM, Nelson ZC, Carroll KA. Relationships between five factor personality variables, workplace accidents and self efficacy. Psychol Rep 2004; 94(3 Pt 2):1437-41.

13- Krejcie RV, Morgan DW. Determining sample size for research activities. Educ Psychol Meas 1970; 30(3):607-10.

14- Costa PT, McCrae RR. NEO PI-R professional manual. Odessa, FL: Psychological Assessment Resources, Inc 1992;

15- Kiamehr J. Standardization of the short form of NEO-FFI-R and investigation of factorial structure (confirmatory analysis) among the humanities' students of Tehran University. [PhD thesis]. Tehran: University of Allame Tabatabai; 2003.

16- Barling J, Loughlin C, Kelloway EK. Development and test of a model linking safety-specific transformational leadership and occupational safety. J Appl Psychol 2002; 78(3):488-96.

17- Munteanu MR. Safety attitudes in the Ontario construction. [MSc thesis]. Canada: University of Toronto; 2005.

18- Kiani F, Samavatyan H, Pourabdian S, Jafari E. Predictive Power of Incidents Reporting Rate and Its Dimensions by Job Stress among Workers' Isfahan Steel Company. Iran J Public Health 2011; 40(3):105-12.

19- Henning JB, Stufft CJ, Payne SC, Bergman ME, Mannan MS, Keren N. The influence of individual differences on organizational safety attitudes. Saf Sci 2009; 47:337-45.

20- Beecher SD, Scott J, Rojas S, Bachard KA. Irritated, stressed, and disturbed: Do neurotic people have more accidents? Paper presented at: The Western Psychological Association Annual Convention; 2008 April; Irvine, England.

21- Wallace C, Chen G. A multilevel integration of personality, climate, self-regulation, and performance. Pers Psychol 2006; 59(3):529-57.

22- Samavatian H, Kamkar M, Negahban $H$. Relationship between personality characteristics with considering safety issues related to work. Psychological Researches 2010; 2(2):48-62.

23- Tucker JS, Elliott MN, Klein DJ. Social control of health behavior: Associations with conscientiousness and neuroticism. Personality and Social Psychology Bulletin 2006; 32(9):1143-52.

24- Foster J. How personality influences safety-related work behavior. The Online Newsletter for Personality Science 2010; Issue 5.

Available from: http://www.personalityarp.org/html/newsletter05/abroad_poland.html

25- Clarke S. Contrasting perceptual, attitudinal and dispositional approaches to accident involvement in the workplace. Saf Sci 2006; 44(6):537-50. 